\title{
SISTEMAS DE PRODUÇÃO ALTERNATIVOS DE TRITICALE, SOB PLANTIO DIRETO, EM PASSO FUNDO, RS ${ }^{1}$
}

\author{
HENRIQUE PEREIRA DOS SANTOS ${ }^{2}$, IVO AMBROSI ${ }^{3}$, JULIO CESAR BARRENECHE LHAMBY \\ e AUGUSTO CARLOS BAIER ${ }^{4}$
}

\begin{abstract}
RESUMO - No período de 1987 a 1991, foram avaliados os efeitos de cinco sistemas de produção de triticale: sistema I (triticale/soja), sistema II (triticale/soja e aveia-preta/soja, de 1987 a 1989, e triticale/soja e aveia-branca/soja, de 1990 a 1991), sistema III (triticale/soja e ervilhaca/milho), sistema IV (triticale/soja, aveia-preta/soja e ervilhaca/milho, de 1987 a 1989, e triticale/soja, ervilhaca/milho e aveia-branca/soja, de 1990 a 1991) e sistema V (triticale/soja, triticale/soja, aveiapreta/soja e ervilhaca/milho, de 1987 a 1989, e triticale/soja, triticale/soja, ervilhaca/milho e aveiabranca/soja, de 1990 a 1991). Usou-se o delineamento de blocos ao acaso, com três repetições e parcelas com área útil de $24 \mathrm{~m}^{2}$. No presente trabalho, apresenta-se a análise econômica relativa àquele período. No período em que as condições climáticas trancorreram normalmente, o sistema III foi a melhor alternativa a ser oferecida aos agricultores, do ponto de vista de rentabilidade. Quando as condições climáticas ocorreram adversamente, o sistema II mostrou maior retorno econômico do que os demais sistemas estudados.
\end{abstract}

Termos para indexação: insumos, custos, receita bruta, receita líquida.

\section{PRODUCTION SYSTEMS ALTERNATIVE FOR TRITICALE, UNDER NO-TILLAGE, IN PASSO FUNDO, RS, BRAZIL}

\begin{abstract}
From 1987 to 1991, in Passo Fundo, RS, Brazil, the effects of production systems on triticale crop were assessed at the Centro Nacional de Pesquisa de Trigo. Five systems for triticale were studied: system I (triticale/soybean), system II (triticale/soybean and black oats/soybean, from 1987 to 1989, and triticale/soybean and white oats/soybean, from 1990 to 1991), system III (triticale/soybean and common vetch/corn), system IV (triticale/soybean, black oats/soybean and common vetch/corn, from 1987 to 1989, and triticale/soybean, common vetch/corn and white oats/soybean, from 1990 to 1991), and system V (triticale/soybean, triticale/soybean, black oats/soybean and common vetch/corn, from 1987 to 1989, and triticale/soybean, triticale/soybean, common vetch/corn and white oats/soybean, from 1990 to 1991). An experimental design of blocks at random with three replications and plots with $24 \mathrm{~m}^{2}$ was used. Economic analysis over that period is presented in this paper. Over the period in which the climatic conditions were normal, system III was the best alternative to be offered to farmers from profitability standpoint. When climatic conditions were adverse, system II showed higher economic return, as compared to the remaining systems studied.
\end{abstract}

Index terms: inputs, costs, gross return, net return.

\section{INTRODUÇÃO}

A importância da rotação de culturas na agricultura do Rio Grande do Sul aumentou com a expansão

\footnotetext{
${ }^{1}$ Aceito para publicação em 12 de agosto de 1998.

${ }^{2}$ Eng. Agr., Dr., Embrapa-Centro Nacional de Pesquisa de Trigo (CNPT), Caixa Postal 451, CEP 99001-970 Passo Fundo, RS. Bolsista do CNPq. E-mail: hpsantos@cnpt.embrapa.br

${ }^{3}$ Economista, M.Sc., Embrapa-CNPT.

${ }^{4}$ Eng. Agr., Dr., Embrapa-CNPT.
}

do plantio direto, que constitui um dos requisitos básicos (FEPAGRO, 1995). Nesse sistema, é fundamental o cultivo de espécies com alta produção de fitomassa, tais como as gramíneas: milho, aveia-preta, aveia-branca, trigo e cevada.

O sistema de rotação mais utilizado pelos agricultores que adotam o plantio direto no Rio Grande do Sul inclui as seguintes culturas: trigo, cevada ou triticale, aveia-preta, aveia-branca e leguminosas, normalmente ervilhaca, no período de outono-inverno; e soja e milho, no período de primavera-verão (Denardin \& Kochhann, 1993). 
Com as culturas de cevada e de trigo, no inverno, e de milho e de soja, no verão, há relativamente poucos trabalhos desenvolvidos para o sul do país. Trabalhos conduzidos por Zentner et al. (1990) com sistemas de produção de cevada e trigo, sob plantio direto, durante três anos, mostraram aumento na receita líquida com apenas um inverno de rotação, em relação à monocultura desses cereais. Os sistemas com dois e com três invernos de rotação ficaram numa posição intermediária. Das espécies estudadas, o milho foi a cultura de maior rentabilidade por hectare.

Pesquisas conduzidas por Santos et al. (1995a, 1995b) com quatro sistemas de produção de cevada e trigo, sob plantio direto, na região de Guarapuava, PR, em dois períodos de estudos (1984 a 1989 e 1990 a 1993), não mostraram diferenças significativas entre as médias quanto à receita líquida. Nas avaliações anuais, dentro de cada experimento, destacouse o sistema com intervalo de um ano de rotação, ou seja, cevada/soja e ervilhaca/milho ou trigo/soja e ervilhaca/milho.

Salomão (1990), em estudos econômicos de sistemas de manejo de solo, com enfoque de análise de decisão para o Estado do Paraná, destaca as maiores produtividades de milho, de soja e de trigo, sob plantio direto, em que os níveis variaram conforme o programa de rotação adotado. Além disso, o plantio direto mostrou desempenho superior em ano climaticamente desfavorável às três espécies, sob qualquer rotação.

De acordo com Fontaneli et al. (1994), na análise econômica de sistemas de rotação que integram lavoura e pecuária, durante três anos, sob plantio direto, o trigo alternado no inverno com pastagem anual de aveia-preta consorciada com ervilhaca e a soja em rotação com milho, em 33\% a 50\% da área, apresentaram maior retorno econômico, em comparação ao sistema de produção de grãos, e ao sistema misto com somente aveia-preta para pastagem.

Por outro lado, em experimento de longa duração com triticale (sistemas de produção de grãos, sob plantio direto), não existe nenhum trabalho no Brasil utilizando análise econômica para indicar qual o melhor sistema a ser oferecido aos agricultores, do ponto de vista de rentabilidade da propriedade agrícola.

O presente trabalho teve por objetivo avaliar economicamente cinco sistemas de produção de triticale.

\section{MATERIAL E MÉTODOS}

O experimento foi instalado na Embrapa-Centro Nacional de Pesquisa de Trigo, município de Passo Fundo, RS, de 1987 a 1991, em Latossolo Vermelho-Escuro distrófico (Brasil, 1973), com delineamento de blocos ao acaso, com três repetições. A área útil da parcela foi de $24 \mathrm{~m}^{2}(3 \mathrm{~m}$ de largura por $8 \mathrm{~m}$ de comprimento). A área experimental vinha sendo cultivada anteriormente com trigo, com aveiapreta e com ervilhaca, no inverno, e com soja, no verão.

Os sistemas de produção avaliados no experimento, tendo o triticale como cultura principal, foram os seguintes: sistema I (triticale/soja), sistema II (triticale/soja e aveia-preta/soja, de 1987 a 1989, e triticale/soja e aveiabranca/soja, de 1990 a 1991), sistema III (triticale/soja e ervilhaca/milho), sistema IV (triticale/soja, aveia-preta/soja e ervilhaca/milho, de 1987 a 1989, e triticale/soja, ervilhaca/milho e aveia-branca/soja, de 1990 a 1991) e sistema V (triticale/soja, triticale/soja, aveia-preta/soja e ervilhaca/milho, de 1987 a 1989, e triticale/soja, triticale/soja, ervilhaca/milho e aveia-branca/soja, de 1990 a 1991) (Tabela 1). Em 1990, nos sistemas IV e V, a troca de posição da ervilhaca/milho por aveia-branca/soja foi com o propósito de possibilitar a semeadura de triticale, após

TABELA 1. Sistemas de produção de triticale, com espécies de inverno e de verão, em plantio direto. Embrapa-CNPT, Passo Fundo ${ }^{1}$.

\begin{tabular}{lccccc}
\hline Sistema de & \multicolumn{5}{c}{ Ano } \\
\cline { 2 - 6 } produção & 1987 & 1988 & 1989 & 1990 & 1991 \\
\hline Sistema I & $\mathrm{Tcl} / \mathrm{S}$ & $\mathrm{Tcl} / \mathrm{S}$ & $\mathrm{Tcl} / \mathrm{S}$ & $\mathrm{Tcl} / \mathrm{S}$ & $\mathrm{Tcl} / \mathrm{S}$ \\
& & & & & \\
Sistema II & $\mathrm{Tcl} / \mathrm{S}$ & $\mathrm{Ap} / \mathrm{S}$ & $\mathrm{Tcl} / \mathrm{S}$ & $\mathrm{Ab} / \mathrm{S}$ & $\mathrm{Tcl} / \mathrm{S}$ \\
& $\mathrm{Ap} / \mathrm{S}$ & $\mathrm{Tcl} / \mathrm{S}$ & $\mathrm{Ap} / \mathrm{S}$ & $\mathrm{Tcl} / \mathrm{S}$ & $\mathrm{Ab} / \mathrm{S}$ \\
Sistema III & $\mathrm{Tcl} / \mathrm{S}$ & $\mathrm{E} / \mathrm{M}$ & $\mathrm{Tcl} / \mathrm{S}$ & $\mathrm{E} / \mathrm{M}$ & $\mathrm{Tcl} / \mathrm{S}$ \\
& $\mathrm{E} / \mathrm{M}$ & $\mathrm{Tcl} / \mathrm{S}$ & $\mathrm{E} / \mathrm{M}$ & $\mathrm{Tcl} / \mathrm{S}$ & $\mathrm{E} / \mathrm{M}$ \\
Sistema IV & $\mathrm{Tcl} / \mathrm{S}$ & $\mathrm{Ap} / \mathrm{S}$ & $\mathrm{E} / \mathrm{M}$ & $\mathrm{Tcl} / \mathrm{S}$ & $\mathrm{E} / \mathrm{M}$ \\
& $\mathrm{Ap} / \mathrm{S}$ & $\mathrm{E} / \mathrm{M}$ & $\mathrm{Tcl} / \mathrm{S}$ & $\mathrm{E} / \mathrm{M}$ & $\mathrm{Ab} / \mathrm{S}$ \\
& $\mathrm{E} / \mathrm{M}$ & $\mathrm{Tcl} / \mathrm{S}$ & $\mathrm{Ap} / \mathrm{S}$ & $\mathrm{Ab} / \mathrm{S}$ & $\mathrm{Tcl} / \mathrm{S}$ \\
Sistema V & $\mathrm{Tcl} / \mathrm{S}$ & $\mathrm{Tcl} / \mathrm{S}$ & $\mathrm{Ap} / \mathrm{S}$ & $\mathrm{Ab} / \mathrm{S}$ & $\mathrm{Tcl} / \mathrm{S}$ \\
& $\mathrm{Tcl} / \mathrm{S}$ & $\mathrm{Ap} / \mathrm{S}$ & $\mathrm{E} / \mathrm{M}$ & $\mathrm{Tcl} / \mathrm{S}$ & $\mathrm{Tcl} / \mathrm{S}$ \\
& $\mathrm{Ap} / \mathrm{S}$ & $\mathrm{E} / \mathrm{M}$ & $\mathrm{Tcl} / \mathrm{S}$ & $\mathrm{Tcl} / \mathrm{S}$ & $\mathrm{E} / \mathrm{M}$ \\
& $\mathrm{E} / \mathrm{M}$ & $\mathrm{Tcl} / \mathrm{S}$ & $\mathrm{Tcl} / \mathrm{S}$ & $\mathrm{E} / \mathrm{M}$ & $\mathrm{Ab} / \mathrm{S}$ \\
\hline
\end{tabular}

1 Ab: aveia-branca (UFRGS 7); Ap: aveia-preta (comum); E: ervilhaca (comum); M: milho (AG 64 A e XL 560); S: soja BR 4); Tcl : triticale (BR 1 e BR 4). 
soja. Isso facilitou comparar o triticale, nos sistemas I e II, que já eram após soja.

Antes da instalação do experimento (abril de 1986), a área foi descompactada, e 4,0 tha ${ }^{-1}$ de calcário foram aplicadas para corrigir a acidez do solo. Inicialmente, a aveiapreta foi semeada (1986) e ceifada com rolo faca na floração plena. A seguir, a soja foi semeada (1986) em plantio direto. As culturas de inverno e de verão foram estabelecidas com semeadora comercial, em plantio direto. Em maio de 1989, antes da semeadura de inverno, foram aplicadas, na superfície, sem incorporação, $2,8 \mathrm{t} \mathrm{ha} \mathrm{h}^{-1}$ de calcário com PRNT 70\%, correspondente à dose máxima recomendada para solo sob plantio direto.

Os rendimentos de grãos de cada espécie, obtidos nos cinco anos de estudo, nos diferentes sistemas de produção de triticale, podem ser observados na Tabela 2.

A análise econômica foi determinada nos cinco sistemas de produção de triticale, com base na receita líquida. Entende-se por receita líquida a diferença entre a receita bruta (rendimentos de grãos das espécies em estudo x preço de venda como produto comercial) e os custos totais [custos variáveis (custos dos insumos + custos das operações de campo) e custos fixos (exemplo: depreciações de máquinas e equipamentos e juros sobre o capital)]. Os preços unitários de venda dos produtos e dos insumos são mostrados na Tabela 3. Os custos com insumos e com as operações de campo foram levantados em outubro de 1994, e para a venda de produtos foram utilizados os preços médios de mercado dos últimos anos.

Os sistemas foram avaliados anualmente (inverno + verão) e na média dos períodos 1987 a 1989 , e 1990 e 1991. No caso da aveia-preta (1987 a 1989) e da ervilhaca (1987 a 1991), foi considerada como rendimento a contribuição ao solo de $90 \mathrm{~kg} \mathrm{ha}^{-1}$ de N (Derpsch et al., 1985; Derpsch \& Calegari, 1992). A divisão do período total do experimento em dois períodos deve-se à substituição, da aveia-preta pela aveia-branca, nos sistemas II, IV e V, a partir de 1990.

TABELA 2. Rendimentos de grãos $\left(\mathrm{kg} \mathrm{ha}^{-1}\right)$ de espécies que compõem cinco sistemas de produção para triticale. Passo Fundo, RS ${ }^{1}$.

\begin{tabular}{|c|c|c|c|c|c|c|c|c|c|c|}
\hline \multirow{3}{*}{$\begin{array}{c}\text { Sistemas } \\
\mathrm{I}\end{array}$} & \multicolumn{10}{|c|}{ Ano } \\
\hline & \multicolumn{2}{|c|}{1987} & \multicolumn{2}{|c|}{1988} & \multicolumn{2}{|c|}{1989} & \multicolumn{2}{|c|}{1990} & \multicolumn{2}{|c|}{1991} \\
\hline & $\mathrm{Tcl}$ & $\mathrm{S}$ & $\mathrm{Tcl}$ & $\mathrm{S}$ & $\mathrm{Tcl}$ & $\mathrm{S}$ & $\mathrm{Tcl}$ & $\mathrm{S}$ & $\mathrm{Tcl}$ & $\mathrm{S}$ \\
\hline & 3.171 & 1.522 & 2.013 & 2.954 & 4.054 & 1.475 & 3.170 & 1.187 & 3.109 & 2.899 \\
\hline \multirow[t]{4}{*}{ II } & $\mathrm{Tcl}$ & $\mathrm{S}$ & $\mathrm{Ap}$ & $\mathrm{S}$ & $\mathrm{Tcl}$ & $\mathrm{S}$ & $\mathrm{Ab}$ & $\mathrm{S}$ & $\mathrm{Tcl}$ & $\mathrm{S}$ \\
\hline & 2.848 & 1.457 & $*$ & 2.776 & 4.333 & 1.437 & 4.074 & 1.071 & 3.280 & 2.642 \\
\hline & Ap & $\mathrm{S}$ & $\mathrm{Tcl}$ & $\mathrm{S}$ & $\mathrm{Ap}$ & $\mathrm{S}$ & $\mathrm{Tcl}$ & $\mathrm{S}$ & $\mathrm{Ab}$ & $\mathrm{S}$ \\
\hline & $*$ & 1.472 & 2.415 & 2.963 & $*$ & 1.566 & 3.083 & 1.042 & 3.797 & 3.116 \\
\hline \multirow[t]{4}{*}{ III } & $\mathrm{Tcl}$ & $\mathrm{S}$ & E & M & $\mathrm{Tcl}$ & $\mathrm{S}$ & E & M & Tcl & $\mathrm{S}$ \\
\hline & 3.078 & 1.470 & * & 7.179 & 3.670 & 2.308 & * & $* *$ & 3.089 & 2.733 \\
\hline & E & $\mathrm{M}$ & Tcl & $\mathrm{S}$ & E & $\mathrm{M}$ & Tcl & $\mathrm{S}$ & E & $\mathrm{M}$ \\
\hline & $*$ & 6.249 & 2.449 & 3.190 & $*$ & 8.312 & 3.279 & 1.279 & $*$ & 5.419 \\
\hline \multirow[t]{6}{*}{ IV } & $\mathrm{Tcl}$ & S & Ap & $\mathrm{S}$ & E & M & $\mathrm{Tcl}$ & $\mathrm{S}$ & E & $\mathrm{M}$ \\
\hline & 2.869 & 1.419 & $*$ & 3.177 & $*$ & 8.436 & 2.360 & 1.218 & $*$ & 5.780 \\
\hline & Ap & $\mathrm{S}$ & E & $\mathrm{M}$ & $\mathrm{Tcl}$ & $\mathrm{S}$ & E & M & $\mathrm{Ab}$ & $\mathrm{S}$ \\
\hline & $*$ & 1.473 & $*$ & 7.034 & 3.319 & 2.092 & $*$ & $* *$ & 3.961 & 3.186 \\
\hline & E & $\mathrm{M}$ & $\mathrm{Tcl}$ & $\mathrm{S}$ & $\mathrm{Ap}$ & $\mathrm{S}$ & $\mathrm{Ab}$ & S & $\mathrm{Tcl}$ & \\
\hline & $*$ & 7.716 & 2.561 & 3.493 & $*$ & 1.915 & 4.521 & 1.059 & 3.483 & 2.630 \\
\hline \multirow[t]{8}{*}{$\mathrm{V}$} & Tcl & $\mathrm{S}$ & Tcl & $\mathrm{S}$ & Ap & $\mathrm{S}$ & $\mathrm{Ab}$ & $\mathrm{S}$ & Tcl & $\mathrm{S}$ \\
\hline & 3.195 & 1.125 & 2.711 & 3.101 & * & 1.796 & 4.443 & 1.005 & 3.405 & 2.707 \\
\hline & $\mathrm{Tcl}$ & $\mathrm{S}$ & Ap & $\mathrm{S}$ & E & $\mathrm{M}$ & $\mathrm{Tcl}$ & $\mathrm{S}$ & $\mathrm{Tcl}$ & $\mathrm{S}$ \\
\hline & 3.052 & 1.033 & $*$ & 3.256 & $*$ & 8.277 & 3.258 & 1.276 & 3.053 & 2.938 \\
\hline & Ap & S & E & $\mathrm{M}$ & $\mathrm{Tcl}$ & $\mathrm{S}$ & $\mathrm{Tcl}$ & $\mathrm{S}$ & E & $\mathrm{M}$ \\
\hline & $*$ & 1.439 & $*$ & 7.356 & 3.250 & 2.312 & 3.070 & 1.045 & $*$ & 5.800 \\
\hline & E & $\mathrm{M}$ & $\mathrm{Tcl}$ & $\mathrm{S}$ & $\mathrm{Tcl}$ & $\mathrm{S}$ & E & M & $\mathrm{Ab}$ & $\mathrm{S}$ \\
\hline & $*$ & 7.158 & 2.036 & 3.169 & 4.513 & 1.652 & $*$ & $* *$ & 3.820 & 3.071 \\
\hline
\end{tabular}

${ }^{1}$ Ab: aveia-branca; Ap: aveia-preta; E: ervilhaca; M: milho; S: soja; Tcl: triticale.

* Culturas para cobertura de solo, no inverno.

** Os rendimentos de milho foram perdidos em função de forte estiagem ocorrida, principalmente, na fase inicial de florescimento. 
TABELA 3. Preço unitário de venda dos produtos e dos insumos utilizados. Os custos com insumos foram levantados em outubro de 1994 e para a venda de produtos foram utilizados os preços médios de mercado dos últimos anos.

\begin{tabular}{|c|c|c|}
\hline Produto & Preço (R\$) & Preço $(\mathrm{R} \$)$ \\
\hline Produtos & Semente & Produto \\
\hline Aveia-preta & $307,00 \mathrm{t}^{-1}$ & $500,00 \mathrm{t}^{-1}$ \\
\hline Aveia-branca & $200,00 \mathrm{t}^{-1}$ & $120,00 \mathrm{t}^{-1}$ \\
\hline Ervilhaca & $706,00 \mathrm{t}^{-1}$ & $500,00 \mathrm{t}^{-1}$ \\
\hline Milho & $2.000,00 \mathrm{t}^{-1}$ & $103,00 \mathrm{t}^{-1}$ \\
\hline Soja & $250,00 \mathrm{t}^{-1}$ & $168,00 \mathrm{t}^{-1}$ \\
\hline Trigo & $220,00 \mathrm{t}^{-1}$ & $117,00 \mathrm{t}^{-1}$ \\
\hline \multicolumn{3}{|l|}{ Fertilizantes } \\
\hline $\mathrm{N}$ & & $500,00 \mathrm{t}^{-1}$ \\
\hline $\mathrm{P}_{2} \mathrm{O}_{5}$ & & $550,00 \mathrm{t}^{-1}$ \\
\hline $\mathrm{K}_{2} \mathrm{O}$ & & $320,00 \mathrm{t}^{-1}$ \\
\hline Calcário & & $26,00 \mathrm{t}^{-1}$ \\
\hline \multicolumn{3}{|l|}{ Fungicidas } \\
\hline Tiabendazole & & $16,30 \mathrm{~kg}^{-1}$ \\
\hline Triadimenol & & $5,20 \mathrm{~kg}^{-1}$ \\
\hline \multicolumn{3}{|l|}{ Herbicidas } \\
\hline $2,4 \mathrm{D}$ & & $5,60 \mathrm{~L}^{-1}$ \\
\hline Atrazine & & $5,20 \mathrm{~L}^{-1}$ \\
\hline Atrazine + metolachlor & & $5,50 \mathrm{~L}^{-1}$ \\
\hline Atrazine + simazine & & $5,20 \mathrm{~L}-^{1}$ \\
\hline Bentazon & & $15,60 \mathrm{~L}^{-1}$ \\
\hline Diuron + paraquat & & $7,80 \mathrm{~L}^{-1}$ \\
\hline Glifosate & & $8,10 \mathrm{~L}^{-1}$ \\
\hline Metribuzin & & $21,00 \mathrm{~L}^{-1}$ \\
\hline Trifluralina & & $3,80 \mathrm{~L}^{-1}$ \\
\hline \multicolumn{3}{|l|}{ Inseticidas } \\
\hline Baculovirus anticarsia & & $0,62 \mathrm{~kg}^{-1}$ \\
\hline Cloropirifós etílico & & $6,40 \mathrm{~L}^{-1}$ \\
\hline Fenvalerato & & $22,00 \mathrm{~L}^{-1}$ \\
\hline Fosfamidon & & $5,04 \mathrm{~L}^{-1}$ \\
\hline Monocrotofós & & $7,10 \mathrm{~L}^{-1}$ \\
\hline Permetrina & & $20,00 \mathrm{~L}^{-1}$ \\
\hline Triclorfon & & $6,66 \mathrm{~L}^{-1}$ \\
\hline Custos: & Variáveis & Fixos \\
\hline Aplicação de calcário & $4,81 \mathrm{ha}^{-1}$ & $2,39 \mathrm{ha}^{-1}$ \\
\hline Aplicação de produtos & $4,19 \mathrm{ha}^{-1}$ & $2,71 \mathrm{ha}^{-1}$ \\
\hline Aplicação de cobertura & $3,60 \mathrm{ha}^{-1}$ & $2,97 \mathrm{ha}^{-1}$ \\
\hline Plantio de aveias, ervilhaca e triticale & $10,98 \mathrm{ha}^{-1}$ & $11,50 \mathrm{ha}^{-1}$ \\
\hline Plantio de milho & $13,73 \mathrm{ha}^{-1}$ & $15,97 \mathrm{ha}^{-1}$ \\
\hline Plantio de soja & $12,35 \mathrm{ha}^{-1}$ & $14,37 \mathrm{ha}^{-1}$ \\
\hline Colheita de aveia-branca e triticale & $21,08 \mathrm{ha}^{-1}$ & $23,28 \mathrm{ha}^{-1}$ \\
\hline Colheita de milho & $32,12 \mathrm{ha}^{-1}$ & $34,92 \mathrm{ha}^{-1}$ \\
\hline Colheita de soja & $23,43 \mathrm{ha}^{-1}$ & $29,10 \mathrm{ha}^{-1}$ \\
\hline Rolagem de aveia-preta & $2,00 \mathrm{ha}^{-1}$ & $1,12 \mathrm{ha}^{-1}$ \\
\hline Tratamento de semente & $0,82 \mathrm{ha}^{-1}$ & 0,00 \\
\hline
\end{tabular}


Nas análises de variância, anuais e conjuntas, consideraram-se como tratamentos as parcelas individuais (culturas) componentes dos sistemas em estudo. Nas análises de variância, considerou-se o efeito tratamento como fixo, e o efeito do ano, como aleatório. A avaliação dos sistemas de produção, em todas as análises, foi realizada pelo teste $\mathrm{F}$, usando-se contrastes (Steel \& Torrie, 1980) que incluem os diferentes tratamentos dos sistemas de produção envolvidos em cada comparação. Essa metodologia de contrastes compara os sistemas dois a dois em uma unidade de base homogênea.

\section{RESULTADOS E DISCUSSÃO}

As receitas líquidas médias, por hectare, proporcionadas pelos cinco sistemas de produção de triticale, e na média conjunta de cada período, estão na Tabela 4.

As análises de variância conjunta dos experimentos referentes à receita líquida, nos dois períodos (1987 a 1989, e 1990 e 1991), apresentaram alta significância nos efeitos anos, sistemas, e interação anos $\mathrm{x}$ sistemas.

Levando-se em conta a receita líquida anual (inverno + verão) do período 1987 a 1989, houve diferenças significativas em todos os anos (Tabela 4). Os sistemas I e III mostraram maior retorno econômico do que o sistema II, em um ano (1989), e não diferiram deste nos outros dois anos (1987 e 1988). Nesse período de estudo, o sistema I não diferiu dos sistemas IV e V. Os sistemas III, IV e V foram superiores ao sistema II, nos três anos estudados. O sistema III foi superior ao sistema IV, em um ano, e não diferiu deste nos outros dois anos. O sistema III foi superior, em dois anos, e não diferiu em um ano, em relação ao sistema $\mathrm{V}$. O sistema IV não diferiu do sistema V, nesse período de estudo.

Na média conjunta de 1987 a 1989, somente o sistema III (R\$ 307,50) foi superior ao sistema II $(\mathrm{R} \$ 84,77)$ quanto à receita líquida (Tabela 4). Por outro lado, o sistema III não diferiu significativamente dos sistemas I (R\$172,05), IV (R\$227,91) e V (R\$ 199,96).

Nesse período de estudo, o triticale produziu relativamente bem (Tabela 2). O destaque foi para a cultura de milho, que apresentou os maiores rendimentos de grãos. Isso repercutiu na receita bruta, e,

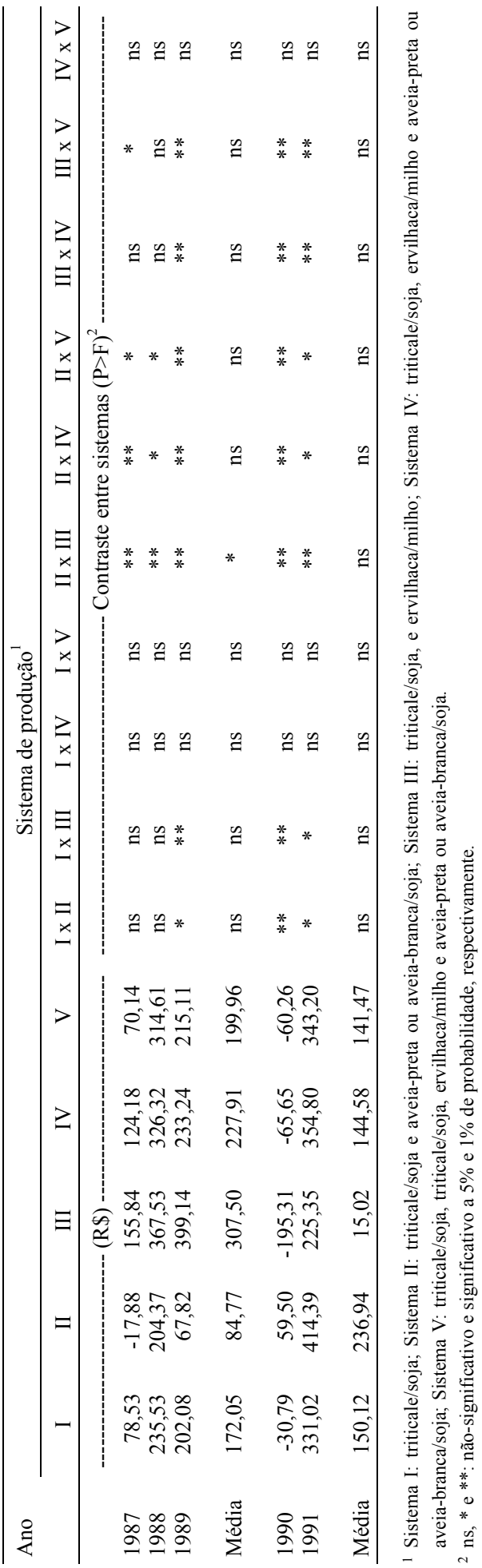


conseqüentemente, na receita líquida dos sistemas III, IV e V. O detalhe é que nos sistemas IV e V havia duas culturas de cobertura de solo (aveia-preta e ervilhaca). Isso favoreceu o sistema III, que continha somente a ervilhaca.

Outro fato que pesou fundamentalmente nisso foi a baixa produtividade da soja em 1987 e em 1989. Deve ser levado em consideração que o sistema III continha apenas uma soja em seus tratamentos, enquanto os sistemas IV e V, duas. Isso igualmente pesou na receita bruta, e, conseqüentemente, na receita líquida desses sistemas.

Em outras palavras, pode-se afirmar que nesse período de estudo as condições climáticas foram relativamente normais para as culturas de inverno e parte das de verão.

Pelas médias anuais, nesse período, o sistema III não diferiu significativamente na maioria dos anos; ou quando diferiu, foi superior aos sistemas I, II, IV e V. Portanto, nesse primeiro período, o sistema III (triticale/soja e ervilhaca/milho) pode ser considerado como a melhor alternativa, caso adotado pelos agricultores, do ponto de vista de rentabilidade.

No Brasil, não há trabalhos de longa duração sobre sistemas de produção de grãos envolvendo triticale, sob plantio direto e com análise econômica. $\mathrm{O}$ trabalho que existe com triticale é sobre rotação de culturas, sem análise da rentabilidade dos sistemas (Santos et al., 1990). Contudo, as pesquisas realizadas por Zentner et al. (1990), de 1984 a 1989, com sistemas de produção de cevada e trigo, sob plantio direto, mostraram resultados semelhantes aos dados obtidos nesse trabalho, ou seja, os sistemas de produção com um inverno de intervalo para estas espécies (cevada/soja e ervilhaca/milho ou trigo/soja e ervilhaca/milho) foram melhores, do ponto de vista de retorno econômico, do que os demais sistemas estudados.

Na média conjunta de 1990 e 1991, o sistema I ( R\$ 150,12) não diferiu significativamente dos sistemas II (R $\$ 236,94)$, III (R \$ 15,02), IV (R \$ 144,58) e V $(\mathrm{R} \$ 141,47)$. Deve ser levado em conta que os sistemas III, IV e V tinham a cultura de milho como um de seus componentes, e essa gramínea não foi colhida em 1990, devido à forte estiagem que ocorreu na fase de florescimento da cultura, o que causou acentuado decréscimo nos valores da receita bruta desses sistemas e indica a importância do milho como fonte de renda. Além disso, a diferença obtida entre o primeiro (1987 e 1989) e o segundo período (1990 e 1991) pode estar relacionada à substituição (em 1990) da aveia-preta pela aveia-branca, nos sistemas II, IV e V, ou seja, cultura de cobertura de solo para produção de grãos (cultura comercial), o que aumentou igualmente a receita líquida, principalmente do sistema II. A aveia-preta poderia ser avaliada pela sua contribuição na engorda de animais, no período de inverno, desde que fosse pastejada.

O triticale, nesse período, continuou produzindo relativamente bem (Tabela 2). O milho que tinha rendido bem, no primeiro período, não foi colhido, em 1990, e produziu relativamente pouco, em 1991. O destaque nesse período foi a cultura de aveia-branca, que rendeu acima dos dados obtidos em anos anteriores e em outros experimentos conduzidos proximamente a este. Isso por si só deve ter benificiado o sistema II, em detrimento dos sistemas III, IV e V que continham a cultura de milho em seus tratamentos.

As condições climáticas foram relativamente boas para as culturas de inverno e ruins para as culturas de verão, principalmente para o milho.

A receita líquida anual (inverno + verão) apresenta diferenças significativas nos anos 1990 a 1991 (Tabela 4). O sistema II foi superior aos sistemas I, III, IV e V, nesse período de estudo. O sistema I, em 1990 e em 1991, foi superior ao sistema III. Nesses dois anos, o sistema I não diferiu significativamente dos sistemas IV e V. Por sua vez, o sistema III, em 1990 e em 1991, foi inferior aos sistemas IV e V. Entre os sistemas IV e V, não houve diferenças significativas entre as médias, nesse período de estudo. Pelas médias anuais de 1990 e de 1991, o sistema II (triticale/soja e aveia-branca/soja) foi a melhor opção, do ponto de vista de retorno econômico, em relação aos demais sistemas estudados, apesar de, na média conjunta do período (1990 e 1991), deles não diferir estatisticamente.

Pelo estudo realizado por Santos et al. (1996), sobre análise de risco desses sistemas, nos mesmos períodos, as alternativas de maior retorno econômico e de menor risco a serem oferecidas aos agricultores foram os sistemas de produção com apenas um ano de intervalo entre as espécies em estudo (siste- 
ma II e III). Deve ser levado em consideração que, como estava previsto, não foi utilizada adubação nitrogenada de cobertura em todas as parcelas que continham milho. Isso pesou, fundamentalmente, na renda líquida dos sistemas III, IV e V, principalmente no primeiro período de pesquisa.

Nos trabalhos conduzidos por Santos et al. (1995a e 1995b), avaliando sistemas de produção de cevada e de trigo, sob plantio direto, em dois períodos (1984 e 1989 e 1990 e 1993), não foram encontradas diferenças significativas entre as médias da receita líquida dos sistemas estudados. Zentner et al. (1990), efetuando análise econômica desse trabalho, no primeiro período, utilizando para o cálculo da receita líquida os preços de maio de 1989, onde US $\$ 1,00=\mathrm{NCR} \$ 55,00$, destacaram o sistema com intervalo de um inverno sem essas gramíneas como os mais rentáveis, em relação aos demais sistemas.

\section{CONCLUSÕES}

1. Quando as condições climáticas transcorrem normalmente, o sistema III é mais eficiente economicamente do que os demais sistemas estudados.

2. Quando as condições climáticas ocorrem adversamente, o sistema II é a melhor opção a ser oferecida aos agricultores, do ponto de vista de retorno econômico.

\section{REFERÊNCIAS}

BRASIL. Ministério da Agricultura. Departamento Nacional de Pesquisa Agropecuária. Divisão de Pesquisa Pedológica. Levantamento de reconhecimento dos solos do Estado do Rio Grande do Sul. Recife, 1973. 421p. (Boletim técnico, 30).

DENARDIN, J.A.; KOCHHANN, R.A. Requisitos para a implantação e a manutenção do sistema plantio direto. In: EMBRAPA. Centro Nacional de Pesquisa de Trigo (Passo Fundo, RS). Plantio direto no Brasil. Passo Fundo: Aldeia Norte/FUNDACEP FECOTRIGO/FUNDAÇÃO ABC, 1993. p.19-27.

DERPSCH, R.; CALEGARI, A. Plantas para adubação verde de inverno. Londrina: IAPAR, 1992. 80p. (IAPAR. Circular, 73).

DERPSCH, R.; SIDIRAS, N.; HEINZMANN, F.X. Manejo do solo com coberturas verdes de inverno. Pes- quisa Agropecuária Brasileira, Brasília, v.20, n.7, p.761-773, jul. 1985.

FEPAGRO. Recomendações técnicas para a cultura do milho no Rio Grande do Sul. Porto Alegre: FEPAGRO/EMATER-RS/FECOTRIGO, 1995. $124 p$.

FONTANELI, R.S.; AMBROSI, I.; DIKESCH, J.A. Análise econômica de sistemas de rotação de culturas para trigo com pastagens anuais de inverno, em plantio direto. In: REUNIÃO CENTRO-SUL DE ADUBAÇÃO VERDE E ROTAÇÃO DE CULTURAS, 4., 1993, Passo Fundo. Anais... Passo Fundo: Embrapa-CNPT, 1994. p.106-110. (Embrapa-CNPT. Documentos, 14).

SALOMÃO, C.C. Sistemas de plantio direto e convencional com enfoque de análise de decisão. Piracicaba: USP-ESALQ, 1990. 127p. Tese de Mestrado.

SANTOS, H.P. dos; REIS, E.M.; BAIER, A.C. Sistemas de cultivo para triticale. I. Efeitos no rendimento de grãos e nas doenças do sistema radicular do triticale, e outras culturas de verão, em plantio direto, $1987 \mathrm{e}$ 1988. In: REUNIÃO BRASILEIRA DE TRITICALE, 3., 1989, Cascavel. Anais... Cascavel: OCEPAR, 1990. p.235-244.

SANTOS, H.P. dos; AMBROSI, I.; IGNACZAK, J.C.; SANDINI, I. Análise econômica de sistemas de rotação de culturas envolvendo soja e cevada, num período de dez anos, sob plantio direto, em Guarapuava, PR. In: REUNIÃO DE PESQUISA DE SOJA DA REGIÃO SUL, 23., 1995, Porto Alegre. Soja: resultados de pesquisa 1994-1995. Passo Fundo: Embrapa-CNPT, 1995a. p.153-163. (EmbrapaCNPT. Documentos, 22).

SANTOS, H.P. dos; AMBROSI, I.; IGNACZAK, J.C.; WOBETO, C. Análise econômica de sistemas de rotação de culturas envolvendo soja e trigo, num período de dez anos, sob plantio direto, em Guarapuava, PR. In: REUNIÃO DE PESQUISA DE SOJA DA REGIÃO SUL, 23., 1995, Porto Alegre. Soja: resultados de pesquisa 1994-1995. Passo Fundo: Embrapa-CNPT, 1995b. p.180-192. (EmbrapaCNPT. Documentos, 22).

SANTOS, H.P. dos; AMBROSI, I.; LHAMBY, J.C.B.; BAIER, A.C. Análise de risco de sistemas de rotação de culturas envolvendo soja e triticale, num período de cinco anos, sob sistema plantio direto, em Passo Fundo, RS. In: REUNIÃO DE PESQUI- 
SA DE SOJA DA REGIÃO SUL, 24., 1996, Pelotas. Soja: resultados de pesquisa do Centro Nacional de Pesquisa de Trigo, 1995-96. Passo Fundo: EmbrapaCNPT, 1996. p.141-152. (Embrapa-CNPT. Documentos, 28).

STEEL, R.G.D.; TORRIE, J.H. Principles and procedures of statistics: a biometrical approach. 2.ed. New York: McGraw-Hill, 1980. 633p.
ZENTNER, R.P.; SELLES, F.; SANTOS, H. dos; AMBROSI, I. Effect of crop rotations on yields, soil characterístics, and economic returns in Southern Brazil. In: INTERNATIONAL WORKSHOP ON CONSERVATION TILLAGE SYSTEMS, 1990, Passo Fundo. Conservation tillage for subtropical areas: proceedings. Passo Fundo: CIDA/EmbrapaCNPT, 1990. p.96-116. 